\title{
Opinion on moderate/low cancer genetic risk markers in medical practice including comment on the article Genetic contribution to all cancers: the first demonstration using the model of breast cancers from Poland stratified by age at diagnosis and tumour pathology by Lubinski et al., Breast Cancer Res Treat 2008 Apr 15
}

\author{
Sandra Costa', Fernando C. Schmitt ${ }^{2}$ \\ 'Life and Health Sciences Research Institute, School of Health Science, University of Minho, Braga, Portugal \\ 2IPATIMUP and Medical Faculty, University of Porto, Porto, Portugal
}

Corresponding author: Fernando C. Schmitt, MD, PhD, IPATIMUP and Medical Faculty, University of Porto, Porto, Portugal, e-mail: fernando.Schmitt@ipatimup.pt

Breast cancer is a heterogeneous disease characterized by a widely variable morphological appearance, many risk factors and distinct gene expression profiles [1, 2]. Common genetic alterations (e.g. polymorphisms), with possible effects on protein function and/or expression, within genes involved in essential cellular pathways, such as carcinogen metabolism, DNA repair, cell cycle control and cell proliferation, can predispose individuals to various tumours, including breast cancer [3-7].

Remarkable efforts have been made to define the genetic susceptibility factors that help to identify women expected to develop breast cancer. The recent study performed by Lubinski et al. [8] is a promising one. This work takes into account several critical points in these types of association studies. First of all, they used a large sample of randomized cancer cases and unaffected matched controls, which produce adequate statistical power (superior to $80 \%$, calculated in http://www.openepi.com/Menu/OpenEpiMenu.htm). A recent report suggests that studies regarding the association between genetic variants and cancer must take into account not only the statistical significance (P-value) but also the false positive report probability (FPRP) [9]. We think that the use of the FPRP criterion will be helpful to validate their results.

Another important improvement made in this work was the stratification of the cases in more homogeneous groups, considering relevant factors in the multifactorial aetiology of this disease, including not only the morphology of the lesion (histological type and grade), but also the hormonal receptor status. This consideration is of extreme importance, since nowadays breast cancer morphological classification is being remodelled using expression profile analysis through cDNA microarrays that can be translated to routine practice using immunohistochemistry for some markers [10]. This approach has redefined breast cancer taxonomy and identified distinct subtypes of carcinomas: luminal (A and B), normal breast-like, HER2 overexpressing and basal-like [2, 10]. These molecular subtypes not only reflect the heterogeneity of breast carcinomas and the possible different cell lineage pathways in breast carcinogenesis, but also demonstrate the difference in clinical outcome. It is quite interesting to see in the results of Lubinski et al. [8] that some markers, such as CDKN24, are associated with ductal carcinomas that were high grade and ER positive, which probably corresponds to the subtype luminal B defined by the molecular classification. It will be very interesting in future studies to look for associations of the different markers with different molecular subtypes of breast carcinomas that could be quite relevant for strategies of prevention and treatment.

Since a large proportion of genetic polymorphisms do not confer a specific phenotypic alteration, selection of the criterion used to choose the genetic susceptibility markers to analyse is critical. A good approach is to include haplotype-tagging polymorphisms investigating genetic variation across the gene or locus, using the phenomenon of linkage disequilibrium. In this way, we think that the authors would improve their results if they performed the genetic polymorphism screening on a vast number of genes and/or loci. Nowadays, technical and bioinformatics resources are available (for example: SNP chips), allowing the assay of several hundred polymor- 
phisms simultaneously, improving the chance of finding a haplotype as a susceptibility marker for the disease [1 1]. The major limitation at this moment for the widespread use of these approaches is that they are very expensive.

In the design of case-control association studies, another determinant feature is the homogeneity between the two groups, minimizing the bias introduced. In our opinion, the authors performed case-control matching well, considering important breast cancer risk factors, such as age, gender, ethnicity, geographic location and cancer family history [1]. It is also well known that prevalence of the genetic variants differs across racial/ethnic and geographic groups [3, 12]. This phenomenon was considered by Lubinski et al. [8], in their study performed in individuals from a specific region of Poland. In this way, their results may or may not be reproducible in other populations, which makes it important to carry out similar studies on them.

To conclude, we believe that the use of moderate cancer genetic risk markers, considering the polymorphic haplotypes in routine practice, will be valuable to delineate primary preventive strategies regarding lifestyle (e.g. diet, exercise) and chemoprevention. In turn, secondary prevention will address public health screening to identify at-risk individuals, allowing physicians to give counselling based on the assessment of genetic risk.

\section{References}

1. Dumitrescu RG, Cotarla I. Understanding breast cancer risk where do we stand in 2005? J Cell Mol Med 2005; 9: 208-221.

2. Perou $C M$, Sørlie T, Eisen MB, van de Rijn $M$, Jeffrey $S S$, Rees $C A$, Pollack JR, Ross DT, Johnsen H, Akslen LA, Fluge $O$, Pergamenschikov A, Williams C, Zhu SX, Lønning PE, BørresenDale AL, Brown PO, Botstein D. Molecular portraits of human breast tumours. Nature 2000; 406: 747-752.

3. Costa S, Pinto D, Pereira D, Rodrigues H, Cameselle-Teijeiro J, Medeiros R, Schmitt F. DNA repair polymorphisms might contribute differentially on familial and sporadic breast cancer susceptibility: a study on a Portuguese population. Breast Cancer Res Treat 2007; 103: 209-217.

4. Gaudet MM, Bensen JT, Schroeder J, Olshan AF, Terry MB, Eng SM, Teitelbaum SL, Britton JA, Lehman TA, Neugut Al, Ambrosone CB, Santella RM, Gammon MD. Catechol-O-methyltransferase haplotypes and breast cancer among women on Long Island, New York. Breast Cancer Res Treat 2006; 99: 235-240.

5. Shin A, Shu XO, Cai Q, Gao YT, Zheng W. Genetic polymorphisms of the transforming growth factor-betal gene and breast cancer risk: a possible dual role at different cancer stages. Cancer Epidemiol Biomarkers Prev 2005; 14: 1567-1570.

6. Dufloth RM, Costa S, Schmitt F, Zeferino LC. DNA repair gene polymorphisms and susceptibility to familial breast cancer in a group of patients from Campinas, Brazil. Genet Mol Res 2005; 4: 771-782.

7. Lee KM, Choi JY, Park SK, Chung HW, Ahn B, Yoo KY, Han W, Noh DY, Ahn SH, Kim H, Wei Q, Kang D. Genetic polymorphisms of ataxia telangiectasia mutated and breast cancer risk. Cancer Epidemiol Biomarkers Prev 2005; 14: 821-825.
8. Lubiński J, Korzeń M, Górski B, Cybulski C, Dębniak T, Jakubowska A, Jaworska K, Wokołorczyk D, Mędrek K, Matyjasik J, Huzarski T, Byrski T, Gronwald J, Masojć B, Lener M, Szymańska A, Szymańska-Pasternak J, Serrano-Fernàndez P, Piegat A, Uciński R, Domagała P, Domagała W, Chosia M, Kładny J, Górecka B, Narod S, Scott R. Genetic contribution to all cancers: the first demonstration using the model of breast cancers from Poland stratified by age at diagnosis and tumour pathology. Breast Cancer Res Treat 2008 Apr 15. [Epub ahead of print].

9. Wacholder S, Chanock S, Garcia-Closas M, El Ghormli L, Rothman N. Assessing the probability that a positive report is false: an approach for molecular epidemiology studies. J Natl Cancer Inst 2004; 96: 434-442.

10. Matos I, Dufloth R, Alvarenga M, Zeferino LC, Schmitt F. p63, cytokeratin 5, and P-cadherin: three molecular markers to distinguish basal phenotype in breast carcinomas. Virchows Arch 2005; 447: 688-694.

11. Erichsen HC, Chanock SJ. SNPs in cancer research and treatment. Br J Cancer 2004; 90: 747-751.

12. Little J, Bradley L, Bray MS, Clyne M, Dorman J, Ellsworth DL, Hanson J, Khoury M, Lau J, O'Brien TR, Rothman N, Stroup D, Taioli E, Thomas D, Vainio H, Wacholder S, Weinberg C. Reporting, appraising, and integrating data on genotype prevalence and gene-disease associations. Am J Epidemiol 2002; 156: 300-310. 